ISSN 1518-3483

Licenciado sob uma Licença Creative Commons

\title{
Educação e empreendedorismo social: um encontro que (trans)forma cidadãos
}

\author{
Education and social entrepreneurship: an \\ encounter that (trans)form citizens
}

\begin{abstract}
Maria Flávia Bastos ${ }^{[a]}$, Ricardo Ferreira Ribeiro ${ }^{[b]}$
[a] Mestre em Gestão Social, Educação e Desenvolvimento Local pelo Centro Universitário Una, Belo Horizonte, BH - Brasil, e-mail: mariaflaviabastos@hotmail.com

[b] Professor Doutor do Mestrado em Gestão Social, Educação e Desenvolvimento Local do Centro Universitário Una, Belo Horizonte, BH - Brasil, e-mail: ricrib@uai.com.br
\end{abstract}

\section{Resumo}

Este trabalho pretende mostrar uma metodologia de ensino fundamentada na possibilidade de formar empreendedores sociais no ambiente escolar e tem como objetivo a implantação de agências experimentais com foco social em instituições de ensino superior de forma inovadora, por meio de recursos motivadores e vivenciais que provoquem nos alunos atitudes criativas, de forma crítica e cidadã. Para a construção da metodologia, foi analisada uma prática já existente, a da agência experimental de empreendedorismo social da Unatec - a Fortuna, implantada pela primeira vez no Brasil 
em 2006 e que criou oportunidades para que os alunos da graduação tecnológica vivenciassem o respeito às diferenças, propondo soluções em comunicação e marketing para entidades do terceiro setor da região metropolitana de Belo Horizonte. Para essa análise, a metodologia de pesquisa utilizada foi a abordagem qualitativa, por meio de entrevistas em profundidade, grupo focal, além de análises bibliográfica e documental. Foram verificados os resultados do impacto social da prática em instituições atendidas, alunos e professores envolvidos no projeto. Esses resultados foram confrontados às teorias do empreendedorismo, do empreendedorismo social, da educação e da gestão social. Com isso, pôde-se perceber que é possível empreender ou vivenciar uma ação transformadora, unindo, em um mesmo momento, alunos, professores e entidades do terceiro setor, por meio de uma proposta educativa diferenciada, em que todos pensam e agem refletindo na busca de transformações sociais significativas.

Palavras-chave: Empreendedorismo social. Educação. Gestão social.

\section{Abstract}

This study aims at showing a teaching methodology based on the possibility of forming social entrepreneurs in the school environment and aims at the establishment of experimental agencies with a social focus in higher education institutions in an innovative way through motivational and experimental resources that provoke the students into creative attitudes, in a critically and citizenship-like attitude. For the methodology construction, we examined an existing practice, the one used by Unatec agency of experimental social entrepreneurship - "Fortune", first introduced in Brazil in 2006, which created opportunities for graduating students in technology to experience respect for differences and propose solutions in communications and marketing for third sector entities in Belo Horizonte metropolitan area. For this analysis, the research methodology used was a qualitative approach through in-depth interviews, focus groups and literature and documental analyzes. Results were checked for the social impact of the practice in attended institutions, students and teachers involved in the project. These results were compared to theories of entrepreneurship, social entrepreneurship, education and social management. Through this, it could be perceived that it is possible for entrepreneurship to happen or to experience a transforming action by joining at the same time, students, teachers and third sector entities through a differentiated 
educational approach, where everyone thinks and acts reflecting the search for meaningful social change.

Keywords: Social entrepreneurship. Education. Social management.

\section{Introdução}

As experiências da Agência Experimental de Empreendedorismo Social Fortuna que aqui serão compartilhadas remeterão, entre outros aspectos, ao eu e tu (filosofia dialógica) ${ }^{1}$ de que fala Martin Buber (1979), como fenômeno essencialmente transformador, em que os sujeitos escutam, falam e silenciam, em uma dinâmica de autorrealização, ajustamento criativo e contato e ao sonho possível - o que se coaduna à proposta pedagógica de Paulo Freire (2001), que entende as mudanças da realidade a partir da participação dos sujeitos que a constituem.

Viver o ensino de empreendedorismo - que hoje se entende ser bem diferente de ensinar empreendedorismo - tem sido a oportunidade de experimentar uma epopeia de emoções em sala de aula. Em um mesmo momento, alunos, professores e entidades do terceiro setor puderam aprender e ensinar por meio de uma proposta educativa diferenciada. Nessa experiência, percebe-se, até mesmo, certo rompimento com a fragmentação, legado da visão cartesiana, tão presente no ambiente escolar (FREIRE, 1996). Investigar, descobrir, apontar e confrontar as teorias do

1 Martin Buber (1979) afirma que não há existência sem comunicação e diálogo e que objetos não existem sem a interação. As palavras-princípio eu-tu (relação) e eu-isso (experiência) demonstram as duas dimensões da filosofia dialógica ou do diálogo, que consiste em uma relação eu-outro, na qual o poder do eu não viole a alteridade do outro, isto é, uma relação que se traduza na preservação absoluta do sujeito, o que inibirá uma iniciativa individualista do eu. Para Buber, a materialidade dessa preservação é o que constitui a 'filosofia do encontro'. 
empreendedorismo com a realidade dos alunos é, finalmente, entender que empreender é vivenciar uma ação (trans)formadora.

Para a construção da metodologia de ensino, a priori, foi estudada a produção teórica do empreendedorismo, do empreendedorismo social, da educação e da gestão social, na intenção de refletir sobre a possibilidade de se gerar mudanças sociais e sistêmicas significativas, tendo como ponto de partida uma troca de experiências entre alunos, professores e entidades do terceiro setor. Em seguida, foi sistematizada e avaliada a prática analisada - a agência experimental de empreendedorismo social, que, como foi dito anteriormente, apresentou uma proposta inovadora, com resultados de impacto social positivo em 45 instituições sem fins lucrativos, tornando-se uma experiência educacional caracterizada por oferecer aos alunos a oportunidade de se prepararem para o mercado de trabalho, com envolvimento em novas ideias e práticas e foco na responsabilidade social.

Como os cursos de tecnólogo do Centro Universitário² têm um perfil voltado prioritariamente para o mercado e uma duração média de dois anos, a experiência da agência tem proporcionado aos estudantes uma oportunidade de vivenciar práticas empresarias e sociais. A problemática do trabalho partiu da possibilidade de, a partir da implantação de uma agência experimental de empreendedorismo social, promover nos alunos de graduação uma nova visão em relação ao processo de empreender. Assim, este trabalho parte da hipótese de que uma agência experimental de empreendedorismo social, implantada em instituições de ensino superior (IES), a partir de uma metodologia de ensino, ${ }^{3}$ poderá promover nos alunos uma nova visão sobre o que significa empreender e provocar, nesses indivíduos, um despertar sobre como exercer de forma diferenciada a prática profissional e social. O objetivo deste trabalho foi, então, o de avaliar e sistematizar a experiência da agência experimental

2 Aqui, a referência é aos cursos avaliados: Comunicação Institucional e Gestão de Marketing.

3 Essa metodologia é apresentada em formato de livreto e apresenta os passos para a implantação da agência de empreendedorismo social, incluindo aí a viabilização do espaço, as dinâmicas e vivências para serem aplicadas em sala com os alunos, dentre outros aspectos. 
de empreendedorismo social do Centro Universitário - e, a partir dos resultados colhidos, propor uma metodologia de ensino para implantação de agências experimentais de empreendedorismo social em IES.

Este estudo se justifica pela necessidade de promover o desenvolvimento do empreendedorismo social - ou de atitudes socialmente empreendedoras - em alunos da graduação, por meio de atividades vivenciais que possibilitam a formação de sujeitos participativos. Outro ponto fundamental da pesquisa é o estudo aprofundado sobre o empreendedorismo social e suas possíveis formas de ensino ou de difusão. Trata-se de um tema ainda pouco explorado, com escassa bibliografia. Há, ainda, confusões entre os termos 'responsabilidade social' e 'empreendedorismo social'. Então, a partir desta pesquisa, será possível também demonstrar que o empreendedoismo social tem como objetivo maior a maximização do capital social existente na realização de iniciativas, projetos e ações que possibilitam, para uma comunidade, cidade ou região, um desenvolvimento participativo.

O projeto da agência experimental de empreendedorismo social que foi desenvolvido e é conduzido pela autora ${ }^{4}$ há pouco mais de três anos - tem contribuído para a modificação da realidade das instituições do terceiro setor atendidas na agência, que, possivelmente, não poderiam pagar pelos serviços lá prestados. Promove-se, com isso, o encontro dos alunos com uma nova realidade, fonte de enfrentamento e de estímulo ao respeito às diferenças e, segundo Freire,

4 A autora do artigo, Maria Flávia Bastos, desenvolveu e conduz a agência experimental há mais de três anos e, com base nessa experiência, sistematizou e avaliou o processo, transformando-o em uma metodologia de ensino. A metodologia de ensino foi fruto do mestrado profissional em Gestão Social, Educação e Desenvolvimento Local do Centro Universitário UNA, em que o também autor deste artigo, Ricardo Ribeiro, foi orientador e, como tal, contribuiu com todo o processo de elaboração do método. É importante esclarecer que a autoria do artigo é, de fato, dos dois autores e que o professor Ricardo Ribeiro, embora não seja o responsável pela criação da metodologia, contribuiu de forma crítica e, portanto, mais distanciada na sistematização da metodologia de ensino aqui descrita. 
à necessidade da invenção da unidade na diversidade. Por isso é que o fato mesmo da busca da unidade na diferença, a luta por ela, como processo, significa já o começo da criação da multiculturalidade. É preciso reenfatizar que a multiculturalidade como fenômeno que implica a convivência no mesmo espaço de diferentes culturas não é algo natural e espontâneo. É uma criação histórica que implica decisão, vontade política, mobilização, organização de cada grupo cultural com vistas a fins comuns. Que demanda, portanto, certa prática educativa coerente com esses objetivos. Que demanda uma nova ética fundada no respeito às diferenças (FREIRE, 1992, p. 157).

Finalmente, este trabalho analisou a relação existente entre a educação em uma instituição de ensino superior, o incremento da participação social no meio discente e docente, o vínculo entre o empreendedorismo social e a educação e a possibilidade de (trans)formar a visão dos alunos para que se tornem sujeitos participativos, empreendedores, pautados nos eixos da sustentabilidade.

\section{Desenvolvimento}

\section{Educação: como (trans)formar nossos alunos}

Supõe-se que a tarefa educativa continua a exigir novos caminhos de perceber e pensar, novas imagens do homem e da sociedade, novas concepções éticas e axiológicas, novos rumos por onde enveredar (BASTOS, 2010). Freire (1992) e Morin (2003) nos mostram que, em muitas instituições de ensino, o principal modo de transmissão do saber ainda é semelhante ao da tradição e da autoridade, em que dirigentes educacionais apontam o saber - que julgam mais necessário e adequado para ser transmitido aos membros da sociedade. E é esse saber já construído que, por vezes, é oferecido sem qualquer convite à reflexão dos alunos.

Em vários momentos da história, o homem necessitou romper as barreiras do conhecimento para ir à busca de um saber reflexivo. 
A educação acadêmica também vem passando por questionamentos acerca dos conceitos e dos significados sobre o que é ensinar e aprender. Uma reflexão acerca da importância de ouvir, respeitar, entender: alunos e professores, na tentativa de construir uma nova dimensão da educação.

A educação do futuro deverá ser o ensino primeiro e universal, centrado na condição humana. Estamos na era planetária; uma aventura comum conduz os seres humanos, onde quer se encontrem. Estes devem reconhecer-se em sua humanidade comum e ao mesmo tempo, reconhecer a diversidade cultural inerente a tudo o que é humano (MORIN, 2003, p. 47).

Foi considerando esses elementos que se vislumbrou o desenvolvimento de novos passos no âmbito de uma nova metodologia de ensino. Acreditou-se na capacidade de reunir saberes por meio de trocas e de reflexões e, assim, foi desenvolvido o Projeto da Agência Experimental de Empreendedorismo Social. Nesse projeto foi proposta uma prática educativa em que um dos objetivos foi o de o professor reforçar a capacidade do aluno de criticar, questionar e construir uma nova realidade pessoal, profissional e social, estimulando sua autoestima, sua criatividade e, ainda, desmistificando, por meio do incremento das atitudes socialmente empreendedoras, o sentido do que seja 'sucesso profissional'.

\section{A educação empreendedora}

No entendimento de Jacques Filion, "o empreededorismo se aprende", pois o autor considera que é possível conceber programas e cursos que adotem sistemas de aprendizados adaptados à lógica desse campo de estudo, em uma abordagem em que o aluno é levado a definir e estruturar contextos e a entender as várias etapas de sua evolução (FILION, 1999, p. 15).

Ocorre que o problema, muitas vezes, não está no professor, mas na instituição universitária, pois desta se requer, hoje, não só a formação de recursos humanos de alto nível de qualificação, mas também 
que proporcione uma educação que prepare para o pleno exercício da cidadania. As estratégias de gestão do projeto pedagógico devem estar voltadas para formar empreendedores que aprendam "a definir os contextos e a tomar decisões de compromisso para melhor definir o conceito sobre si mesmo" implicando que o "aluno deve desenvolver uma relação pró-ativa com o aprendizado" (FILION, 1999, p. 15).

Embora haja diversas definições vindas de autores de épocas distintas, o empreendedorismo ainda é um assunto novo que tem crescido também nas escolas nos últimos tempos. É nesse contexto de afirmação do incremento intelectual, da valorização do conhecimento como gerador de ideias inovadoras e que caracterizam as ações realizadas por empreendedores que se situam, principalmente, as experiências no ensino superior. A educação com foco na formação de empreendedores torna-se fundamental diante dos novos desafios impostos pela sociedade de modo geral e pelo mercado de trabalho em particular, o que não significa transformar a sala de aula em espaço de disseminação de uma cultura que imponha a formação de um sujeito "empregável".

Empregáveis, mercadoria para o emprego? Esta é uma das imagens mais reducionistas dos educandos e dos currículos. É a imagem que mais tem marcado o que ensinamos e privilegiamos em nossa docência. Foi assim que a Lei n. 5.692/71 via as crianças, adolescentes e jovens: candidatos a concursos, a vestibulares, ao segmentado mercado de emprego. Esta visão reducionista marcou as décadas de 1970 e 1980 como hegemônica e ainda está presente e persistente na visão que muitas escolas têm de seu papel social e na visão dos alunos como empregáveis é determinante nos formuladores de políticas de currículo (ARROYO, 2007, p. 24).

A formação de empreendedores baseia-se em estimular o aluno a buscar e experimentar a inovação, criar coisas novas, deixar a mente fluir, as ideias correrem soltas até se transformarem em possíveis oportunidades. Mas como formar alunos com capacidade empreendedora nas universidades? Um dos caminhos mais comuns é a implantação das 
chamadas agências juniores ou experimentais, espaços onde os alunos, em princípio, vivenciam a experiência mercadológica. A empresa júnior constitui-se numa organização que está ligada a uma IES, e é gerida inteiramente por alunos, em todos os seus aspectos. Os trabalhos efetuados em seu âmbito são supervisionados por professores, e a finalidade principal é estabelecer uma relação entre a teoria e a prática do processo de ensino, além de uma melhor qualificação profissional. Essa organização não visa lucro e seu foco principal é preparar jovens profissionais para o mercado de trabalho (OLIVEIRA, 2008, p. 12).

\section{A contribuição de Martin Buber, Fernando Dolabela e Paulo Freire}

O diálogo, segundo Martin Buber, é o princípio de tudo. É dizer alguma coisa para alguém, é estabelecer uma relação com algo que cause alguma reação ou que toque profundamente. Sua percepção quanto ao diálogo vai muito além da ideia de analisar de forma semântica ou lógica a estrutura da linguagem. É por meio da palavra e do próprio ato de pronunciá-la que, para Buber, o homem pode ser inserido na existência. Ele acredita que o diálogo não se restringe à linguagem falada, pois "a linguagem pode renunciar a toda mediação de sentidos e ainda assim é linguagem" (BUBER, 1982, p. 35).

Buber afirma que o mundo pode ser duplo para o homem variando de acordo com sua opção em proferir a palavra-princípio eu-tu ou eu-isso. As atitudes que fundamentam o mundo do tu são totalmente diferentes das que fundamentam o mundo do Isso. O eu-tu faz referência a um ato essencial do homem, a uma atitude de encontro entre dois parceiros na reciprocidade e na confirmação mútua, ou seres da relação dialógica. Já o eu-isso, representa o mundo experimental, das ideias e dos conceitos, com atitudes objetivadas, onde está contido o modelo sujeito e objeto, definindo-nos como seres de relacionamento objetivante. Nesse encontro, não é necessário que um deva abrir mão do seu jeito, suas opiniões ou peculiaridades. Faz-se necessário apenas que um aceite o outro 
como um ser que diverge dele nos mais variados aspectos. Tornando-se alguém único. O diálogo de Buber tem como base o respeito mútuo dessas diferenças. Na filosofia do eu-tu, o afastamento entre o sujeito e o objeto acontece quando o homem extravasa suas sensações físicas e se vê dono de sensações próprias, podendo distinguir-se de seu ambiente.

Ao traçar um paralelo entre a filosofia de Buber e a educação com foco no empreendedorismo e no empreendedorismo social percebe-se uma forma humanizada de lidar com as pessoas, estimulando-as a construir suas próprias verdades, crenças, valores, respeitando a si mesmo e o outro. Uma formação empreendedora na perspectiva buberiana terá como base a formação de um sujeito integral, que perceba o outro de forma dialógica, experimentando e construindo sua visão sobre o mundo. Esse sujeito terá virtudes questionadoras e perceberá que pode ser único, pleno e não mais tentar criar um estereótipo de homem de sucesso ou perfeito a partir de crenças e valores próprios. Na educação empreendedora não há fórmulas prontas ou técnicas específicas, mas sim, propostas conjuntas que proponham o autoconhecimento, o conhecimento do outro e do mundo e a construção de um sujeito mais completo. Na metodologia de ensino proposta há uma série de atividades, baseadas em dinâmicas e vivências que fazem com que o aluno possa dialogar e se encontrar com ele mesmo, com os colegas, com os professores, com a escola, com a comunidade atendida e, por fim, com a realidade social que o cerca.

No caso de Dolabela e Freire, os autores, de maneiras diferentes, mas não antagônicas, tratam o sonho como elemento fundamental na formação do indivíduo: de forma crítica, consciente, humanizada. Longe de ser abordagens ingênuas, o pensamento desses autores em relação ao sonho, será aqui abordado, debatido e comparado às experiências vividas na agência experimental de empreendedorismo social. $\mathrm{O}$ sonho a que se refere Dolabela está relacionado à concepção de futuro, de forte desejo. Para ele, "o empreendedor é alguém que sonha e busca transformar o seu sonho em realidade" (2008) e, a partir disso, gerar e distribuir riquezas.

Em sua Pedagogia Empreendedora - metodologia de ensino de empreendedorismo para a educação básica - são trabalhadas com os 
alunos duas questões: (1) Qual é o meu sonho?; (2) O que vou fazer para transformar o meu sonho em realidade?. A partir desses questionamentos, a metodologia trabalha no desenvolvimento do aluno em empreender em atividades que tenham a ver com a realização de seus sonhos: seja no governo, no terceiro setor, nas grandes empresas, como artistas, pesquisadores etc. o tema central da pedagogia de Dolabela não é o enriquecimento pessoal, mas a participação do indivíduo, de forma ativa e inovadora, na construção do desenvolvimento social. Fernando Dolabela entende que é preciso que os alunos "desenvolvam o potencial de sonhar (DOLABELA, 2008, p. 13). Para tanto, o autor acredita que, a princípio,

a escola precisa entender o que é empreendedorismo. Isso é difícil porque não existe uma consciência da importância do termo. Todos nós fomos formados num ambiente não-empreendedor porque o modelo de inserção no mundo profissional seguia (e ainda segue) a relação emprego na indústria. A escola deve introduzir o empreendedorismo no currículo como uma disciplina normal ou, melhor ainda, inseri-lo de forma transversal, que é um processo mais complexo. $\mathrm{Na}$ introdução do conceito, recomendo a utilização do espaço curricular convencional. Depois, é importante que o empreendedorismo seja algo muito diverso do ensino convencional (DOLABELA, 2008, p. 15).

Já para Paulo Freire, em sua Pedagogia dos sonhos possíveis, sonhar significa

imaginar horizontes de possibilidades; sonhar coletivamente é assumir a luta pela construção das condições de possibilidade. A capacidade de sonhar coletivamente, quando assumida na opção pela vivência da radicalidade de um sonho comum, constitui atitude de formação que orienta-se não apenas por acreditar que as situações-limite podem ser modificadas, mas fundamentalmente, por acreditar que essa mudança se constrói constante e coletivamente no exercício crítico de desvelamento dos temas-problemas sociais que as condicionam. $\mathrm{O}$ ato de sonhar coletivamente, na dialeticidade da denúncia e do anúncio e na assunção do compromisso com a construção dessa superação, carrega em si um importante potencial (trans) formador que produz e é 
produzido pelo inédito viável, visto que o impossível se faz transitório na medida em que assumimos coletivamente a autoria dos sonhos possíveis (FREIRE, 2001, p. 30).

E, como é comum nos textos do autor, Freire nos convida, a partir da prática educativa, a (trans)formar uma geração de alunos que tenham nítida percepção do contexto social, político, tecnológico da realidade excludente e, ainda, da possibilidade de gerar mudanças a partir de ações coletivas, conscientes, transformadoras. Nessa perspectiva, o que propõe a metodologia de ensino, é uma abordagem dos problemas vividos pelas organizações atendidas e pelas comunidades em que essas instituições estão inseridas, de forma que possam compreender a realidade e, a partir dela, de forma conjunta, propor/criar condições de mudança social.

\section{(Trans)formar alunos com foco na gestão social}

O mundo atual está repleto de novas perspectivas sociais, econômicas, políticas, comportamentais. E, portanto, acaba exigindo ações diferenciadas das organizações - sejam elas com ou sem fins lucrativos; privadas, públicas ou do terceiro setor - e dos profissionais responsáveis por sua gestão. Transformações pós-revolução industrial, como a concentração humana nas cidades, acarretaram graves problemas sociais e ambientais. E com a crise do modelo fordista - no fim da década de 70 - novos valores são inseridos no cenário mundial: direitos humanos, democracia, preservação ambiental. Surgem, com isso, novos modelos de gestão: agora mais flexíveis. Com o fenômeno da globalização e a diminuição do "tempo e do espaço", que unem fronteiras, culturas e ideias, há um crescimento na participação das pessoas nas principais decisões mundiais.

Essa perspectiva gera uma discussão conceitual e sugere novas ideias de como trabalhar a gestão das organizações nesse novo cenário. Assim, depois de entendermos que estamos vivendo uma nova realidade mundial, é preciso compreender como deverá ser a forma de gerenciar as 
organizações, adaptando-se, agora, a outra realidade. Como lidar com o pensamento estratégico, a capacidade criativa, a percepção e a escolha dos instrumentos de gestão? Surge a gestão social, um modelo que substitui, segundo Tenório (2002, p. 197),

a gestão tecnocrática, monológica, por um gerenciamento participativo, dialógico, no qual o processo decisório em uma dada sociedade é exercido por meio dos diferentes sujeitos sociais. Este conceito sugere que a pessoa humana ao tomar ciência de sua função como sujeito social e não adjunto, ou seja, tendo conhecimento da substância social do seu papel na organização da sociedade, deve atuar não somente como contribuinte, eleitor, trabalhador, mas com uma presença ativa e solidária nos destinos de sua comunidade.

Na gestão social, a esfera prioritária é a social. Nesse sentido, a gestão social se diferencia da gestão privada, que prioriza a esfera econômico-mercantil (BOULLOSA, 2009).

O que o termo gestão social sugere é que, para além do Estado, a gestão das demandas e necessidades do social pode se dar pela própria sociedade, por meio de suas diversas formas de auto-organização, em maior ou menor articulação com o Estado (SCHOMMER, 2010).

E o gerente social, responsável por essa nova forma de gestão, deverá ser apto ao debate, às discussões e negociações com os chamados atores sociais envolvidos no processo organizacional. Pois, em gestão social, o trabalho é "com", é de diagnóstico e tomada de decisão coletiva. Com tudo isso, há ainda um grande afastamento entre a teoria e a prática. Daí, a importância da formação e da viabilidade de se aumentar o número de gestores sociais. Para Alves e Moura, a formação desse novo gestor pode ter, como ferramenta, metodologias não convencionais de ensino, um conceito que

surgiu no bojo de práticas de desenvolvimento local em áreas de exclusão, que instigaram uma profunda reflexão sobre as teorias e os métodos em uso na Gestão Social e na construção de Políticas Públicas. 
O apelo para a virada paradigmática que as $\mathrm{MnCs}$ representam e concretizam origina de um movimento paralelo de reflexão teórica e observação das práticas. As abordagens participativas na gestão social e na construção de políticas públicas parecem hoje teoricamente inescapáveis, pelas características estruturais de nossas sociedades complexas, e, ao mesmo tempo, praticamente insatisfatórias (ALVES; MOURA, 2009, p. 1).

Os gestores do futuro deverão adquirir competências por meio de cursos que apresentem metodologias diferenciadas, "assumidamente não tecnicistas; que visam propiciar a produção de conhecimento interativo; que pretendem valorizar as competências reais dos sujeitos envolvidos em cada processo e mobilizar na esfera pública toda a riqueza do humano" (ALVES; MOURA, 2009, p. 3). Com isso, os graduandos poderão tornar-se profissionais dotados de uma visão ao mesmo tempo analítica, sensível e intuitiva. Prontos para propor ações organizacionais coletivas, multiplicando oportunidades de desenvolvimento e cidadania. Nesse contexto, a proposta da metodologia de ensino de implantação de agência de empreendedorismo social pode ser considerada uma Metodologia não Convencional que estimula e estimulará nos alunos, dentre outros aspectos, a formação em gestão social.

\section{A metodologia da pesquisa}

Entendendo que essa pesquisa avaliou e sistematizou uma prática educativa e, a partir de seus resultados, propôs uma metodologia de ensino, o tipo de pesquisa utilizada foi a qualitativa, com abordagem descritiva/ comparativa. A escolha desse método se deve também e, principalmente, ao fato de que a autoria do projeto da Agência Experimental - assim como a responsabilidade pela sua condução prática - é da autora deste artigo. É uma condição especial ser partícipe do projeto, o que não impossibilita que haja o distanciamento necessário ao desenvolvimento do olhar cientifico, crítico, exigido por uma pesquisa. 
Essa condição é colocada por Lakatos como uma vantagem, pois na pesquisa qualitativa, o pesquisador assume o papel de observador e interpretador da realidade para então descrevê-la e explicá-la. Para a autora, a interpretação dos fenômenos e a atribuição de significados são básicas no processo de pesquisa qualitativa, permitindo que não seja necessária a utilização de métodos e técnicas estatísticas. A coleta de dados é feita no ambiente natural e o pesquisador é o instrumento-chave (LAKATOS; MARCONI, 1986).

Fazem parte do projeto da agência experimental de empreendedorismo social três grupos distintos, mas que estão interligados nos processos de trabalho: 1) os alunos, que escolhem as entidades a serem atendidas e oferecem a elas um diagnóstico e um planejamento na área de comunicação e marketing; 2) as instituições atendidas, que, depois de apontadas pelos alunos, vão, durante o processo, mostrar seu funcionamento e "abrir as portas" de sua organização para análise e intervenção; 3) os professores, que, durante o semestre, trabalham com os alunos no desenvolvimento do projeto - que é interdisciplinar. Os procedimentos metodológicos para a realização da pesquisa obedeceram aos seguintes passos: a) determinação dos materiais e da bibliografia a ser analisada; b) determinação dos critérios e contato com os entrevistados; c) elaboração das pesquisas; d) realização das pesquisas; e) transcrição e análise dos dados; f) desenvolvimento da metodologia de ensino. Para tanto, utilizou-se, na ordem apresentada, as seguintes ferramentas: 1) pesquisa bibliográfica; 2) pesquisa e análise documental; 3) observação participante; 4) entrevistas semiestruturada; 5) grupo focal.

\section{A metodologia de ensino}

Essa metodologia é apresentada no formato de um livreto com ilustrações e formato compacto que demonstram a criatividade e a concepção lúdica que a metodologia pretende estimular nos seus participantes. A capa do livreto encontra-se no anexo deste artigo. O objetivo do desenvolvimento dessa metodologia é contribuir para a (trans)formação 
de alunos, professores e instituições do terceiro setor comprometidos com o fim da desordem e da desigualdade social que ainda imperam hoje. Esse roteiro de prática profissional cidadã é fruto de um trabalho pioneiro no país e que se propõe a implementar nas escolas de ensino superior caminhos sustentáveis para o estímulo ao empreendedorismo social. E esses caminhos, serão apenas guiados por esse roteiro. Caberá a cada professor, a cada aluno, a cada escola, a cada instituição atendida, enveredar nesse percurso, seus sonhos e sua história, parte de um destino que não terá fim.

A agência experimental de empreendedorismo social deve se estabelecer na instituição de ensino como uma espécie de laboratório que estimule a descobrir seus talentos, respeitar as diferenças encontradas dentro do grupo que pertence e na comunidade a ser atendida. O que se pretende, com a implantação desse tipo de agência é:

1) estimular a criatividade, a inovação, o espírito empreendedor e a cidadania nos alunos;

2) (trans)formar os alunos de forma empreendedora para suas ocupações no mercado, independente de sua escolha profissional (dono do próprio negócio, empregado, voluntário...);

3) estimular o encontro e o respeito às diferenças.

Nesse artigo, serão apresentados alguns dos itens do roteiro para a implementação de agências experimentais de empreendedorismo social em IES. Trata-se de um guia para a elaboração de um espaço que tem como objetivo a vivência do empreendedorismo social. De forma coletiva, o programa prevê, dentre outros ganhos, a descoberta de novos talentos, o aumento da auto-estima e do autoconhecimento de seus participantes.

\section{Passo a passo}

Infraestrutura: ter um espaço físico para a agência experimental é de suma importância para o processo do envolvimento dos alunos e 
dos professores com o projeto. Envolvimento na construção/adaptação do espaço: é preciso trabalhar a intervenção dos alunos e professores no espaço existente. Escolha de nome e logomarca: para essa etapa sugere-se um concurso para a escolha do nome e da logomarca da nova agência. Escolha de missão e valores: a missão de uma organização é a sua razão de ser. E os valores, seus pilares de sustentação. Assim, é de fundamental importância a definição desses dois itens. Envolvimento institucional da: direção; coordenação de curso; coordenação do projeto. Professores: por ser um projeto interdisciplinar, necessita do total envolvimento dos docentes para o estímulo dos discentes. São esses professores, independente de sua área de conhecimento, os disseminadores da cultura empreendedora. Se forem disseminar essa cultura, é preciso primeiro que desejem junto aos alunos empreender também. Para isso, será necessário estimular esse professor, levando a sentir vontade de estimular seus alunos e, de fato, iniciar com eles um diálogo e um processo de novas descobertas.

A agência parte de um curso: é interessante manter a agência em cursos que ofereçam disciplinas que tragam para os debates a gestão e o empreendedorismo em suas vertentes tradicional e social. Os cursos que poderão receber a agência são os de marketing, comunicação, administração, informática, design, cursos de gestão da graduação tecnológica, e outros que a escola e julgar pertinentes. A agência formado por cursos afins: o projeto também pode ser intercursos como marketing e comunicação; marketing e design, ou outras formas que a escola julgar pertinente. $A$ agência intercursos: outra possibilidade é a junção de vários cursos da instituição envolvidos para atender uma mesma organização. Para tanto, o que se sugere é uma divisão do espaço por Núcleos, como por exemplo: Núcleo de Sustentabilidade e qualidade de vida; Núcleo de Inovação em Produtos e Serviços; Núcleo de Trabalho e Renda; Núcleo de Negócios e Oportunidades; Núcleo de Economia Popular; Núcleo de Inclusão Digital; Núcleo de Saúde. Tempo de duração e carga horária do projeto: o projeto deverá ter a duração de dois períodos ou dois semestres. No primeiro, os alunos fazem o contato com a entidade, desenvolvem o diagnóstico e o planejamento estratégico. Na segunda etapa, no semestre seguinte, o grupo 
irá a campo para auxiliar a instituição na implantação do projeto. Sorteio dos grupos: em função do objetivo central do projeto que é o encontro, o lidar com as diferenças, a metodologia prevê que os grupos de trabalho dos alunos sejam sorteados. Essa dinâmica é, a princípio, desconfortável e por vezes causa conflitos. Mas com o tempo, conforme se avaliou no projeto já existente, o método torna-se eficaz e até mesmo prazeroso. Escolha das instituições: trata-se de um processo que requer cuidado e respeito. A escolha da organização a ser atendida deverá partir dos grupos, já que eles passarão um bom tempo junto à entidade, buscando soluções conjuntas. Esse envolvimento só é possível quando há identificação do grupo com o tema/atividade da ONG. Assim, a imposição de atendimento faz com que seja muito difícil a integração, processo natural, gradativo e tão singular em projetos dessa natureza. Desenvolvimento do projeto: quando os alunos voltam à sala de aula após a primeira visita, caberá ao professor a avaliação do material trazido: fotos, comentários, percepções. A partir desse conjunto, inicia-se o processo de análise e construção das propostas de trabalho para as instituições atendidas. Essas propostas, à medida que vão sendo desenvolvidas, vão sendo debatidas em sala de aula entre os componentes do grupo, com os professores das disciplinas do semestre e com a entidade atendida. O produto ou os produtos desse processo de desenvolvimento dependerá do curso ou cursos que estarão envolvidos no programa. Dinâmicas de apoio: há todo momento aponta-se como fundamental o papel motivador do professor coordenador junto aos alunos. Esse professor tem diversas tarefas a cumprir durante todo o processo como realização de eventos, criação de roteiros, desenvolvimento dos projetos. Embora cada atividade seja feita de forma conjunta, sabe-se ser o professor, o sujeito preparado para estimular e envolver os participantes e fazê-los entender os objetivos do programa. Para isso, sugere-se o uso de vivências em grupo que são ótimos recursos motivadores. Elas são fundamentais para o entrosamento, o envolvimento entre alunos e professores e, consequentemente, dos alunos com as entidades atendidas. Conceitos: nessa metodologia os conceitos teóricos trabalhados são os da educação, do empreendedorismo e da gestão social. Avaliação do 
programa: como trata-se de um projeto prioritariamente participativo e que não tem um modelo permanente mas sim, pronto para ser melhorado a cada dia, é preciso avaliar seu andamento e sua evolução. Sistematizar os resultados é de grande importância. Para tanto, sugere-se os dois momentos avaliativos que se seguem: avaliações periódicas e avaliação dos resultados: Ao término de cada semestre é muito bom que a coordenação do projeto realize um seminário com a participação dos envolvidos para um debate amplo que levará as questões apontadas nas avaliações periódicas. Esse evento deverá ser documentado com fotos, gravação e/ou filmagem. Depois, deverá ser avaliado de forma conjunta e sistematizadas as adaptações que se fizerem necessárias à metodologia.

O que se espera, de fato, é que os passos apresentados apontem para a descoberta de novos caminhos na instituição de ensino - diretoria, docentes, discentes e comunidade - de forma a experimentar novas formas de ensinar e aprender o empreendedorismo e a gestão social com respeito e prazer.

\section{Conclusão}

Durante o processo vivido na construção dessa nova metodologia foram quebrados velhos paradigmas, colocados novos desafios e incluídos novos sonhos sociais e profissionais. Foi percebido o que, de fato, está acontecendo no cenário social e empresarial do nosso país e do mundo afora. Auferiu-se sobre a nova lógica de participação e sobre a segunda forma de pensar e agir na gestão. Assim, há espaço para um profissional mais sensível, mas não menos estratégico. Há espaços para alguém que perceba as nuances da participação popular de forma efetiva e que consiga intercambiar ideais e ideias num novo contexto que vai chegando mais próximo de nós a cada dia, onde tempo e espaço já não mais representam limites.

Diante dessas novas inquietações e novidades, foi sistematizado o que já era feito intuitivamente com os alunos da agência experimental Fortuna. Percebeu-se que era hora de colocar no papel e na prática uma maneira de (trans)formar esses alunos em cidadãos, prontos para 
mudar as práticas de injustiça, desigualdade e desperdício que ainda vive-se hoje em dia.

O propósito maior era provocar ainda mais esses alunos e alunas para que protagonizem uma história diferente. Mas, para propor esse método "provocador" e "não convencional", houve dificuldades. É preciso compreender a complexidade de um processo de sistematização de uma experiência e sua transformação em uma nova proposta, principalmente quando a experiência estudada foi desenvolvida e coordenada pela autora desse artigo e da metodologia de ensino desde 2006. Diante disso, vislumbrou-se nessa nova metodologia de ensino proposta perspectivas, desafios e limitações.

No caso das perspectivas, entende-se que a metodologia pode ser um caminho para o desenvolvimento da cidadania e do empreendedorismo no ambiente escolar. Os desafios estão em, por meio do método, incutir nos participantes do projeto o desejo de inovar, de criar, de explorar e de conhecer o diferente, de quebrar paradigmas e partir para uma nova forma de ensinar, aprender e construir outra realidade social. E por fim, no quer tange às limitações, as dificuldades serão em trabalhar o empreendedorismo de forma a não vinculá-lo somente como ferramenta para abrir um novo negócio, mas como forma de ultrapassar os próprios limites, conhecer-se, expandir-se. Essa é uma realidade ainda nova nas disciplinas de empreendedorismo ofertadas no país. Assim, compreende-se que esse trabalho pode despertar nas instituições de ensino superior o desejo de investir mais e sempre na (trans)formação de seus alunos. Podendo e pretendendo incentivar a prática de empreender e empreender socialmente no ambiente escolar, por meio de uma metodologia que objetiva ser uma ferramenta que criará oportunidades de mudança social. Trata-se da possibilidade de construir novas relações, novas chances, novos encontros, novas responsabilidades, novas pessoas. Trata-se de um desafio pessoal que pretende agora, ser de muitos, ser de todos, ser, enfim, um modelo para ser vivido e partilhado. 


\section{Referências}

ALVES, V. G.; MOURA, M. S. de S. O potencial de uma virada paradigmática: metodologias não convencionais na formação do gestor social. In: COLÓQUIO INTERNACIONAL SOBRE PODER LOCAL, 11., 2009, Salvador. Anais... Salvador: Colóquio Internacional sobre Poder Local, 2009.

ARROYO, M. G. Indagações sobre currículo: educandos e educadores: seus direitos e o currículo. Brasília: Ministério da Educação, Secretaria de Educação Básica, 2007. Disponível em: <http://portal.mec.gov.br/seb/arquivos/pdf/ Ensfund/indag2.pdf $>$. Acesso em: 5 nov. 2009.

BASTOS, S. Por que me sinto realizado em ser pedagogo? Belo Horizonte: Centro Universitário UNI BH, 2004. Material didático.

BOULLOSA, R. de F. Contribuições conceituais e metodológicas para a avaliação de processos e práticas de gestão social a partir das perspectivas da policy analysis e da abordagem social da aprendizagem. In: COLÓQUIO INTERNACIONAL SOBRE PODER LOCAL, 11., 2009, Salvador. Anais... Salvador: Colóquio Internacional sobre Poder Local, 2009.

BUBER, M. Eu e tu. Tradução de Newton Aquiles von Zuben. 2. ed. São Paulo: Cortez \& Moraes, 1979.

BUBER, M. Do diálogo e do dialógico. São Paulo: Perspectiva, 1982.

CARNEIRO, C. B. L.; COSTA, B. L. D. Gestão social: o que há de novo? Belo Horizonte: Fundação João Pinheiro, 2004. Disponível em: <http://www.eg.fjp. mg.gov.br/index.php/component/docman/doc_details/262-gestao-social-o-que-ha-de-novo-desafios-e-tendencias >. Acesso em: 15 jan. 2010.

DOLABELA, F. 0 ensino de empreendedorismo no Brasil: uma metodologia revolucionária. Disponível em: <http://www.projetoe.org.br/tv/prog10/html/ ar_10_01.html . Acesso em: 5 jun. 2008. 
FILION, L. J. Empreendedorismo: empreendedores e proprietários-gerentes de pequenos negócios. Revista de Administração de Empresas, São Paulo, v. 34, n. 2, p. 5-28, 1999.

FREIRE, P. Pedagogia do oprimido. Rio de Janeiro: Paz e Terra, 1979.

FREIRE, P. Extensão ou comunicação. Rio de Janeiro: Paz e Terra, 1980.

FREIRE, P. Pedagogia da esperança. Rio de Janeiro: Paz e Terra, 1992.

FREIRE, P. Pedagogia da autonomia: saberes necessários à prática educativa. São Paulo: Paz e Terra, 1996.

FREIRE, P. Pedagogia dos sonhos possíveis. São Paulo: UNESP, 2001.

LAKATOS, E. M.; MARCONI, M. de A. Metodologia do trabalho científico: procedimentos básicos, pesquisa bibliográfica, projeto e relatório, publicações e trabalhos científicos. 2. ed. São Paulo: Atlas, 1986.

MORIN, E. Os sete saberes necessários à educação do futuro. São Paulo: Cortez, 2003.

OLIVEIRA, E. M. Empreendedorismo social: da teoria à prática, do sonho à realidade. Rio de Janeiro: Qualitymark, 2008.

SCHOMMER, P. C. Gestão social: caso de inovação em políticas públicas ou mais um caso de Lampedusa? Disponível em: <http://institutofonte.org.br/ artigo-gestao-social-inovacao-enigma-de-lampedusa>. Acesso em: 20 jan. 2010.

TENÓRIO, F. G. Tem razão a administração? Ensaios de teoria organizacional e gestão social. Ijuí: Ed. Unijuí, 2002.

Recebido: 17/08/2010

Received: 08/17/2010

Aprovado: 10/10/2010

Approved: 10/10/2010 